\title{
BMJ Open Prevalence and associated factors of post-traumatic stress disorder among emergency responders of Addis Ababa Fire and Emergency Control and Prevention Service Authority, Ethiopia: institution-based, cross-sectional study
}

\author{
Yodit Habtamu Bezabh, ${ }^{1}$ Solomon Mekonnen Abebe, ${ }^{2}$ Tolesa Fanta, ${ }^{1}$
} Agitu Tadese, ${ }^{1}$ Mikiyas Tulu ${ }^{1}$

To cite: Bezabh YH, Abebe SM, Fanta T, et al. Prevalence and associated factors of posttraumatic stress disorder among emergency responders of Addis Ababa Fire and Emergency Control and Prevention Service Authority, Ethiopia: institution-based, crosssectional study. BMJ Open 2018;8:e020705. doi:10.1136/ bmjopen-2017-020705

- Prepublication history for this paper is available online. To view these files, please visit the journal online (http://dx.doi org/10.1136/bmjopen-2017020705).

Received 20 November 2017 Revised 31 May 2018 Accepted 20 June 2018

A) Check for updates

(c) Author(s) (or their employer(s)) 2018. Re-use permitted under CC BY-NC. No commercial re-use. See rights and permissions. Published by BMJ.

${ }^{1}$ Amanuel Mental Specialized Hospital, Addis Ababa, Ethiopia ${ }^{2}$ College of Medicine and Health Science, Institute of Public Health, University of Gondar, Gondar, Ethiopia

Correspondence to Dr Solomon Mekonnen Abebe; solomekonnen@yahoo.com

\section{ABSTRACT}

Objective To assess the prevalence and associated factors of post-traumatic stress disorder (PTSD) among emergency responders at Addis Ababa Fire and Emergency Control and Prevention Service Authority, Ethiopia. Design Institution-based, cross-sectional design. Setting The study was conducted at the Fire and Emergency Control and Prevention Service Authority, Addis Ababa, Ethiopia.

Participants 603 emergency responders who worked in the Fire and Emergency Control and Prevention Authority during the study period.

Measurement Data were collected using a selfadministered questionnaire: an adaptation of the standardised PTSD Checklist-Civilian Version. The questionnaire was administered to subjects on duty. Social support was measured using the 0slo 3-Item Social Support Scale, while other stressful life events were measured using the List of Threatening Experiences, that is, experiencing one or more stressful life events in the last 6 months. Reliability and construct validity were verified. To be diagnosed with PTSD, a subject must display at least three different types of symptoms at once. Coded variables were entered into Epi Info V.3.5.1 and then exported to SPSS V.20 for analysis. Descriptive and bivariate and multivariate logistic regressions and $95 \% \mathrm{Cl}$ were employed to establish and test statistically significant associations.

Results A total of 603 subjects participated in the study, with $19.9 \%$ prevalence rate of PTSD $(95 \% \mathrm{Cl} 16.9$ to 23.1$)$. The study found family history of mental illness (adjusted $\mathrm{OR}(\mathrm{AOR})=2.82 ; 95 \% \mathrm{Cl} 1.65$ to 4.84$)$, longer years of service (AOR=2.67; 95\% Cl 1.54 to 4.63), as well as prolonged exposure to emergency situations $(\mathrm{AOR}=0.44$; $95 \% \mathrm{Cl} 0.24$ to 0.84 ) and road traffic accidents (AOR=2.71; $95 \% \mathrm{Cl} 1.67$ to 4.42 ) as significant predictors of PTSD among emergency responders.

Conclusion The prevalence of PTSD was high among the study population. Family history of mental illness, length of service, duration of exposure and type of exposure were found to be associated with PTSD. Mental health education

\section{Strengths and limitations of this study}

- The consistently stable reliability and construct validity of the PTSD Checklist-Civilian Version scale in the current study can be used as a reference in subsequent studies.

- Recall biases might have occurred among subjects while completing the questionnaire.

- By design, the limitation of the study emanates from its cross-sectional design, which may have only partially accounted for durable temporal relationships.

- The results are drawn from probabilistic samples and they are only generalisable to populations with similar underlying profile and in the context of a low-income/middle-income country.

and linking emergency responders with available mental health services/facilities should be prioritised to mitigate the problem.

\section{INTRODUCTION}

\section{Background/rationale}

Post-traumatic stress disorder (PTSD) is a mental disorder that potentially follows an event in which an individual experiences, witnesses or confronts either actual or probable loss of life or a serious injury, invoking a response of fear, helplessness or horror. ${ }^{1}$ Globally, about $14 \%$ of the burden of disease has been attributed to neuropsychiatric disorders, mostly due to the chronic nature of depression and other common mental disorders. ${ }^{2}$ The WHO's global burden of disease survey estimates that mental disease, including stress-related disorders, will be the second leading cause of disability by year 2020. ${ }^{3}$ The prevalence of PTSD varies 
extremely among different populations. Within high-income countries, ${ }^{4-7}$ for instance, the lifetime prevalence of PTSD varies from $0.3 \%$ to $8.7 \%$.

This study focuses on professional emergency responders, including firefighters, ambulance personnel, and search and rescue workers or first responders, ${ }^{8}$ who are oftentimes exposed to both direct and indirect stressors, such as risking their own life to enter burning buildings, jumping into waters to rescue drowning persons and witnessing the suffering of others. ${ }^{9}$ In many cases, these experiences induce psychological and physiological stress reactions, which lead to physical pain, mental disorders and substance abuse. ${ }^{10}$ In other words, these professionals' occupational experiences are high in stress levels, inducing acute PTSD. ${ }^{11}$

Consequently, the estimated prevalence of PTSD among emergency responders $(1.3 \%-15 \%)$ in high-income countries ${ }^{12-14}$ is significantly higher than the prevalence rate in the general population. Specifically, the prevalence of PTSD among firefighters in high-income countries ranges between $22.2 \%$ in the USA (and 22\% in the UK) and $12.1 \%$ in Sweden, while $17.3 \%$ in Canada and $18.2 \%$ in Germany. ${ }^{15} 16$ On the other hand, PTSD among London ambulance personnel was found to be lower at 6\%. ${ }^{1718}$ The situation in South Africa shows 16\% of university-educated paramedic trainees have PTSD, ${ }^{19} 20$ and this percentage depicts a relatively high prevalence as compared with the occurrence of PTSD among emergency responders in middle-income and low-income countries, that is, $1.6 \%-15 \% .^{1921}$

Studies document age, sex and social capital as factors mostly associated with the occurrence of PTSD among emergency responders. Specifically, those with low socioeconomic status, with dysfunctional family unit or have lost a family member are highly prone to PTSD. ${ }^{1422-25}$ Longer shift hours (more time spent per day on the job), distressing missions, and assisting survivors or being in close contact with victims are mostly associated with PTSD, whereby professionals could feel utmost fear and personal threat. The presence of a previously experienced trauma of any nature could aggravate the occurrence of PTSD. ${ }^{14}$ 25-27

Studies reveal that due to the nature of their occupations, emergency responders carry high risks of developing PTSD, which generally leads to loss of ability to function well in social and professional environments, and affects their quality of life. ${ }^{28}$ The economic and social impact of PTSD is felt by those who experience the disorder, and by families, coworkers, employers and the wider society. ${ }^{23}$ Ordinarily, it increases job dissatisfaction, work absenteeism or early retirement among victims. Moreover, general social impairments increase more than 17-fold due to PTSD. 2224

Currently in Ethiopia, urbanisation has been associated with increasing fire, road traffic and construction-related accidents, adding to the preponderance of situations which expose emergency responders to various traumatic or stressful events. Consequently, a combination of rising prevalence and long-term complications, coupled with the alarming rate of urbanisation, will surely increase the burden of disease on the country's health system. However, little is known about this burden in Ethiopia as well as in Africa.

\section{Objective}

This study set out to assess the prevalence and associated factors of PTSD among emergency responders by taking the case of Addis Ababa Fire and Emergency Control and Prevention Service Authority (AFECA).

\section{METHODS}

\section{Study design}

The study employed an institution-based, cross-sectional study. It was conducted from May 2016 to June 2016.

\section{Study setting}

The study was conducted at AFECA. Addis Ababa, the capital city of Ethiopia, with its 10 subcities and 99 districts, lay at the foothills of Mount Entoto. The city has an elevation of $2360 \mathrm{~m}$ above sea level, with an estimated area of 526.99 square kilometres, density of 5165.1 people per square kilometre and a total population of 3384569 , with an annual growth rate of $3.8 \%$ (Central Statistics Agency, 2007).

The city has one service provider for fire and other emergency situations, that is, AFECA. Established in 1926 European Calendar, AFECA experienced modest expansions as it opened new branches and diversified the types of service it provides to the residents of the city.

\section{Study participants/subjects}

The study includes all emergency responders on standby at AFECA during the study period. In total, there were 470 firefighters, 150 ambulance nurses and 40 search and rescue workers on the payroll of the Authority. We excluded those participants who were not directly involved in the emergency response of the Fire and Emergency Control and Prevention Service (such as administrative staff who were working at the office level) and those on leave during the study period.

\section{Sample size determination}

The minimum number of samples required for this study was estimated using the single population proportion formula with the following assumptions: the national proportion of prevalence and associated factors of PTSD are unknown in Ethiopia, $\mathrm{p}=0.5$ was used; $\mathrm{Z}$ (standard normal distribution: 1.96) was assumed and CI was set at $95 \%$ (and $=0.05$ ); and a non-response rate of $10 \%$. Accordingly, a representative/probabilistic sample size of the study was calculated to be 423. After considering all the extraneous factors that could increase non-response rate among subjects, the authors decided to include all emergency responders on the Authority's payroll $(n=660)$. 


\section{Study variables}

This study has three dependent variables: PTSD, other stressful life events and social support. The dependent variable PTSD was measured as a dichotomous variable (yes/no) on 17 items of the PTSD Checklist-Civilian Version (PCL-C), with the cut-off point set at greater than or equal to 50 , that is, emergency responders who scored less than 50 had no PTSD and those who scored $\geq 50$ had PTSD. Furthermore, to be diagnosed with PTSD, a person must have three different types of symptoms: re-experiencing of the trauma, numbing of affect and avoidance of trauma-related stimuli, and symptoms of excessive arousal not present before the event and must have lasted more than 1 month. ${ }^{29}$

Independent variables include sociodemographic factors (age, sex, marital status, ethnicity, educational status, type of profession, income), clinical variables (history of mental illness, previous childhood traumatic experience, family history of mental illness), work-related factors (service year, type of exposure, duration of exposure, number of exposures) and psychosocial factors (social support, other stressful life event, perceived threat).

In this study, emergency responders are professionals who work in emergency situations such as attending to car accidents, fires, drownings and any other disasters. These professionals are firefighters, ambulance personnel (nurses) and search and rescue workers.

\section{Data sources and measurement}

Data were collected via a self-administered structured questionnaire. The questionnaire was administered to subjects on standby, who were expected to complete and return it to the supervisors on the spot unless they were too busy or called for duty. In the latter case, they were allowed to take the instrument home, complete and return it the other day. Supervisors had a BSc Degree in Psychiatric Nursing, and they were trained to explain unclear questions, orient subjects on the questionnaire as well as the ethical principles of confidentiality/ anonymity and data management prior to involvement in data collection, secure subjects' informed consent for participation, distribute copies of the questionnaire, and collect the completed and returned questionnaires.

Data on the magnitude of PTSD were collected using a standard questionnaire. The PCL-C is a general civilian version, and questions refer to 'a stressful experience in the past'; it is an easily administered self-report rating scale for assessing 17 Diagnostic and Statistical Manual of Mental Disorders (DSM)-IV symptoms of PTSD. ${ }^{30}$ A total symptom severity score (range $=17-85$ ) could be obtained by summing the scores from each of the 17 items, which had response options ranging from ' $1=$ not at all' to ' $5=$ extremely', with a cut-off $\geq 50$ on PCL treated as a predictor of PTSD. It showed high internal consistency, reliability and strong correlation with PTSD diagnosis using a clinician-administered PTSD scale. The authors conducted a reliability analysis for the Amharic translated versions of the PCL-C, which had high reliability score (Cronbach's $\alpha=0.96$ ). The scale was computed by summing each item. Higher scores indicated the probability of PTSD, while lower scores indicated no/less PTSD. The authors preferred to use the PCL-C rather than the PCL-S since the emergency responders could be and have been exposed to different kinds of traumatic events not only for specific traumatic events that feature in the life conditions of a specific population. Two studies of both Vietnam and Persian Gulf theatre veterans showed that the PCL was both valid and reliable.

Social support was measured using the Oslo 3-Item Social Support Scale, a self-report measure of support with high internal consistency (Cronbach's $\alpha=0.50$ ) in a study done at Bayero University, Kano, Nigeria, ${ }^{31}$ and with scores ranging between 3 and 14: 3-8=poor social support; 9-11=intermediate social support; and 12-14=strong social support. On the other hand, 'perceived threat' was measured in terms of respondents' affirmative response to the question 'Do you feel the situation is threatening to you?' Reliability and construct validity were good.

Other stressful life events were measured using the List of Threatening Experiences. The presence of stressful life events was explained by having experienced one or more stressful life events in the past 6 months starting from the time of the study. The revised version of this instrument has 10 items with a dichotomous yes/no response categories. The scale had reliability (alpha coefficient of 0.74 ) in this study.

\section{Data quality management}

The questionnaire was designed in English (by integrating the three standard tools) and was translated to Amharic and back to English, that is, forward and backward translation. A 1-day training was organised for supervisors. The questionnaire was pretested on $5 \%$ of the sample population of the Ethiopian Airlines Department of Emergency Services for 2 days to check its reliability to be deployed in the main survey. Based on the findings of the pretest, the questionnaire was revised and adapted, and a summary of the pretesting exercise is included in this report.

\section{Statistical methods}

First, the data were checked for completeness and consistency. For analysis, coded variables were entered into Epi Info V.3.5.1, then exported and analysed using SPSS V.20. Descriptive statistics were used to explain the subjects in relation to study variables. Bivariate binary logistic regression analysis was performed to assess the factors that affect the occurrence/likelihood of PTSD. Variables in the bivariate analysis with a $p$ value of $<0.2$ were entered into the multivariable logistic regression analysis to control for confounders, and the results were expressed as adjusted ORs (AOR). A 95\% confidence level was used to determine factors associated with PTSD, 
Table 1 Distribution of sociodemographic factors of study participants in Addis Ababa Fire and Emergency Control and Prevention Service Authority, Addis Ababa, Ethiopia, 2016 $(n=603)$

\begin{tabular}{|c|c|c|}
\hline Characteristics & Frequency & Percentage \\
\hline \multicolumn{3}{|l|}{ Age } \\
\hline $18-24$ & 167 & 27.7 \\
\hline $25-34$ & 307 & 50.9 \\
\hline $35-44$ & 106 & 17.6 \\
\hline$>45$ & 23 & 3.8 \\
\hline \multicolumn{3}{|l|}{ Sex } \\
\hline Female & 132 & 21.9 \\
\hline Male & 471 & 78.1 \\
\hline \multicolumn{3}{|l|}{ Marital status } \\
\hline Married & 288 & 47.8 \\
\hline Single & 289 & 47.9 \\
\hline Others* & 26 & 4.3 \\
\hline \multicolumn{3}{|l|}{ Ethnicity } \\
\hline Amhara & 227 & 37.6 \\
\hline Oromo & 190 & 31.5 \\
\hline Tigre & 69 & 11.4 \\
\hline Gurage & 60 & 10.0 \\
\hline Others & 57 & 9.5 \\
\hline \multicolumn{3}{|l|}{ Educational status } \\
\hline $\begin{array}{l}\text { 10th and 12th } \\
\text { complete }\end{array}$ & 182 & 30.2 \\
\hline Diploma & 314 & 52.1 \\
\hline Degree & 107 & 17.7 \\
\hline \multicolumn{3}{|l|}{ Type of profession } \\
\hline Firefighter & 459 & 76.1 \\
\hline Ambulance nurse & 113 & 18.7 \\
\hline $\begin{array}{l}\text { Search and } \\
\text { rescue }\end{array}$ & 31 & 5.1 \\
\hline \multicolumn{3}{|l|}{ Income } \\
\hline $1500-2500$ & 123 & 20.4 \\
\hline $2600-3600$ & 391 & 64.8 \\
\hline$>3700$ & 89 & 14.8 \\
\hline
\end{tabular}

*Others: divorced, widowed and separated.

that is, a $p$ value of $<0.05$ was considered statistically significant.

\section{Ethical considerations}

The purpose of the study was explained to the participants. The consent form indicated that participation was voluntary and that clients had the right to withdraw from completing the questionnaire at any time without reason. Participants were also informed that there was no guarantee of preferential treatment or any associated benefits and risks associated with the study. All data collected were used for academic purposes only. None of the data collected contained subjects' identifying information, ensuring their anonymous responses. Completed questionnaires and computer data were kept confidential with codes. Data were stored on a computer and protected by password known only to the authors.

\section{Patient and public involvement}

In the current study our study participants are people who are working at Addis Ababa Fire, Emergency Control and Prevention Service Authority, and patients were not included in this study. Our study participants were also not involved in the study design and recruitment. The results of this study will be disseminated to the Emergency Control and Prevention Service Authority and the Federal Ministry of Health through presentation and policy briefing.

\section{RESULTS}

\section{Subjects' sociodemographic characteristics}

A total of 603 participants took part in the study, with a response rate of $91.4 \%$. Three-quarters of the participants $(78.1 \%)$ were male, nearly half $(47.9 \%)$ were single and more than one-third $(37.6 \%)$ were of Amhara ethnicity (the second largest ethnic group of the country). Half of them (52.1\%) were diploma graduates, and the same proportion $(50.9 \%)$ was in the age range of 25-34 years. Three-quarters of the respondents $(76.1 \%)$ were firefighters, nearly one-fifth (18.7\%) were ambulance nurses and one-twentieth (5.1\%) were search and rescue workers. More than half of the participants $(64.8 \%)$ were in the income group of 2600-3600 birr (table 1).

\section{Subjects' clinical profiles}

Twenty (3.3\%) of the participants had history of mental illness, $5(5.0 \%)$ experienced physical abuse and neglect during childhood, and $50(15.1 \%)$ had family history of mental illness (table 2).

Table 2 Distribution of clinical factors of study participants in Addis Ababa Fire and Emergency Control and Prevention Service Authority, Addis Ababa, Ethiopia, $2016(n=603)$

\begin{tabular}{lcc}
\hline Characteristics & Frequency & Percentage \\
\hline $\begin{array}{l}\text { History of mental illness } \\
\text { No }\end{array}$ & 583 & 96.7 \\
Yes & 20 & 3.3 \\
Childhood trauma (physical abuse and neglect) \\
No & 573 & 95.0 \\
Yes & 30 & 5.0 \\
Family history of mental illness & & \\
No & 512 & 84.9 \\
Yes & 91 & 15.1 \\
\hline
\end{tabular}


Table 3 Distribution of work-related and type of exposures of study participants in Addis Ababa Fire and Emergency Control and Prevention Service Authority, Addis Ababa, Ethiopia, 2016 ( $n=603)$

\begin{tabular}{|c|c|c|c|}
\hline Characteristics & Category & Frequency & Percentage \\
\hline \multirow[t]{3}{*}{ Service year } & $\leq 3$ years & 342 & 56.7 \\
\hline & 4-5years & 129 & 21.4 \\
\hline & $>5$ years & 132 & 21.9 \\
\hline \multirow{3}{*}{$\begin{array}{l}\text { Duration } \\
\text { exposure }\end{array}$} & $<3$ hours & 89 & 14.8 \\
\hline & $3-4$ hours & 114 & 18.9 \\
\hline & $>5$ hours & 400 & 66.3 \\
\hline \multirow{15}{*}{$\begin{array}{l}\text { Type of } \\
\text { exposures }\end{array}$} & Fire accident & & \\
\hline & No & 143 & 23.7 \\
\hline & Yes & 460 & 76.3 \\
\hline & Road traffic crash & & \\
\hline & No & 475 & 78.8 \\
\hline & Yes & 128 & 21.2 \\
\hline & Drowning & & \\
\hline & No & 581 & 96.4 \\
\hline & Yes & 22 & 3.6 \\
\hline & Dead person & & \\
\hline & No & 515 & 85.4 \\
\hline & Yes & 88 & 14.6 \\
\hline & Other & & \\
\hline & No & 517 & 85.7 \\
\hline & Yes & 86 & 14.3 \\
\hline \multirow{4}{*}{$\begin{array}{l}\text { Number of } \\
\text { exposures }\end{array}$} & $<10$ times & 191 & 31.7 \\
\hline & 10-20 times & 208 & 34.5 \\
\hline & 30-40 times & 100 & 16.6 \\
\hline & $>40$ times & 104 & 17.2 \\
\hline
\end{tabular}

\section{Main results}

Subjects' work-related exposure (outcome) to PTSD

The exposure of subjects to PTSD varied in terms of type and duration of their work. Specifically, the duration of exposure of $400(66.3 \%)$ subjects to stressful working conditions was $\geq 5$ hours, and three-quarters $(76.3 \%)$ of them were exposed to fire accidents. More than half $(56.7 \%)$ of the subjects had less than 3 years of work experience in the Authority and one-third of them (34.5\%) were exposed 10-20 times (table 3).

Out of the total of 603 participants, nearly one-fifth $(18.1 \%)$ reported perceived threat, half (51.9) had moderate social support and the overwhelming majority $(99.5 \%)$ had other stressful life events (table 4) that accompanied their work experience.

The overall prevalence of PTSD among emergency responders at the Authority was found to be 120 (19.9\% (95\% CI 16.9 to 23.1)). Of the $19.9 \%$ prevalence of PTSD, the percentages of ambulance nurses and firefighters were, respectively, $11.5 \%$ (95\% CI 6.2 to 17.0 ) and $20.7 \%$ (95\% CI 17.2 to 24.8 ). The prevalence among search and
Table 4 Distribution of psychosocial factors for study participants in Addis Ababa Fire and Emergency Control and Prevention Service Authority, Addis Ababa, Ethiopia, 2016 $(\mathrm{n}=603)$

\begin{tabular}{lll}
\hline Characteristics & Frequency & Percentage \\
\hline Perceived threatening & & \\
No & 494 & 81.9 \\
Yes & 109 & 18.1 \\
Social support & & \\
$\quad$ Poor & 221 & 36.7 \\
Moderate & 313 & 51.9 \\
$\quad$ Strong & 69 & 11.4 \\
Other stressful life events & \\
No & 3 & 5 \\
Yes & 600 & 95.5 \\
\hline
\end{tabular}

rescue workers was $38.7 \%$, which is significantly higher than the overall prevalence in the total sample, that is, $19 \%$.

\section{Factors associated with PTSD}

Bivariate analysis of PTSD found age, marital status, family history of mental illnesses, length of service, duration of exposure, road traffic accident exposures and number of exposures were significant predictors of PTSD at a $p$ value less than 0.2 . These predictors were then entered into the multivariable logistic regression model to control for their confounding effects (table 5).

The result of the multivariate analysis showed that family history of mental illness, years of service, prolonged exposure and exposure to road traffic accidents were significantly associated with PTSD. The odds of developing PTSD among participants with family history of mental illness were about three times higher than those who had no such family history (AOR=2.82; 95\% CI 1.65 to 4.84). The odds of developing PTSD were more than two times higher among participants who had $4-5$ years of work experience than those who had less than 3 years of work experience (AOR=2.67; 95\% CI 1.54 to 4.63). On duration of exposure, the odds of developing PTSD among those who were exposed for greater than 5 hours decreased by $56 \%$ compared with those who were exposed for less than 3 hours (AOR=0.44; 95\% CI 0.24 to 0.84 ). The odds of developing PTSD were more than two times higher among those who were exposed to road traffic accidents than those who had not had exposure to road traffic accidents (AOR=2.71; 95\% CI 1.67 to 4.42 ) (table 5).

\section{DISCUSSION}

Emergency responders were usually exposed to both direct and indirect stressors, such as risking their lives when entering a burning building, rescuing a drowning person or witnessing the suffering of others. ${ }^{32}$ In many 
Table 5 Bivariable and multivariable independent predictors of PTSD among emergency responders in Addis Ababa Fire and Emergency Control and Prevention Service Authority, Addis Ababa, Ethiopia, 2016 ( $n=603)$

\begin{tabular}{|c|c|c|c|c|c|}
\hline \multirow[b]{2}{*}{ Variables } & \multirow[b]{2}{*}{ Total $(F, \%)$} & \multicolumn{2}{|l|}{ PTSD } & \multirow[b]{2}{*}{ COR $(95 \% \mathrm{Cl})$} & \multirow[b]{2}{*}{ AOR $(95 \% \mathrm{Cl})$} \\
\hline & & No & Yes & & \\
\hline \multicolumn{6}{|l|}{ Age } \\
\hline $18-24$ & $167(27.7)$ & $147(30.4)$ & $20(16.7)$ & 0.91 (0.25 to 3.33$)$ & $0.28(0.06$ to 1.31$)$ \\
\hline $25-34$ & $307(50.9)$ & $248(51.3)$ & 59 (49.2) & 1.59 (0.46 to 5.52$)$ & $0.49(0.12$ to 2.06$)$ \\
\hline $35-44$ & $106(17.6)$ & $68(14.1)$ & $38(31.7)$ & $3.73(1.04 \text { to } 13.36)^{\star}$ & 1.21 (0.29 to 4.99$)$ \\
\hline$>45$ & $23(3.8)$ & $20(4.1)$ & $3(2.5)$ & 1 & 1 \\
\hline \multicolumn{6}{|l|}{ Marital status } \\
\hline Married & $288(47.8)$ & $231(47.8)$ & $57(47.5)$ & 1 & 1 \\
\hline Single & $289(47.9)$ & $238(49.3)$ & $51(42.5)$ & 0.87 (0.57 to 1.32$)$ & 1.15 (0.69 to 1.90$)$ \\
\hline Otherst & $26(4.3)$ & $14(2.9)$ & $12(10.0)$ & $3.47(1.52 \text { to } 7.92)^{\star *}$ & 1.59 (0.61 to 4.16$)$ \\
\hline \multicolumn{6}{|c|}{ Family history of mental illness } \\
\hline No & $512(84.9)$ & $427(88.4)$ & $85(70.8)$ & 1 & 1 \\
\hline Yes & $91(15.9)$ & $56(11.6)$ & $35(29.2)$ & $3.14(1.94 \text { to } 5.09)^{\star \star \star}$ & $2.68(1.56 \text { to } 4.59)^{\star \star \star}$ \\
\hline \multicolumn{6}{|l|}{ Service year } \\
\hline$\leq 3$ years & $342(56.7)$ & $292(60.5)$ & $50(41.7)$ & 1 & 1 \\
\hline $4-5$ years & $129(21.6)$ & $83(17.2)$ & $46(38.3)$ & $3.24(2.03 \text { to } 5.17)^{\star \star *}$ & $2.59(1.49 \text { to } 4.51)^{\star \star \star}$ \\
\hline$>5$ years & $132(21.9)$ & $108(22.4)$ & $24(20.0)$ & 1.29 (0.76 to 2.21$)$ & 0.85 (0.41 to 1.77$)$ \\
\hline \multicolumn{6}{|c|}{ Duration of exposure } \\
\hline$<3$ hours & $89(14.8)$ & $67(13.9)$ & $22(18.3)$ & 1 & 1 \\
\hline $3-4$ hours & $114(18.9)$ & $78(16.1)$ & $36(30.0)$ & 1.41 (0.75 to 2.62$)$ & 1.24 (0.62 to 2.46$)$ \\
\hline$\geq 5$ hours & $400(66.3)$ & $338(70.0)$ & $62(51.7)$ & $0.56(0.32 \text { to } 0.97)^{\star}$ & $0.44(0.24 \text { to } 0.84)^{\star \star}$ \\
\hline \multicolumn{6}{|c|}{ Road traffic crash type exposure } \\
\hline No & $475(78.8)$ & $399(82.6)$ & $76(63.3)$ & 1 & 1 \\
\hline Yes & $128(21.2)$ & $84(17.4)$ & $44(36.7)$ & $2.75(1.77 \text { to } 4.27)^{\star \star \star}$ & $2.71(1.66 \text { to } 4.42)^{\star \star \star}$ \\
\hline \multicolumn{6}{|c|}{ Number of exposure } \\
\hline$<10$ times & $191(31.7)$ & $153(31.7)$ & $38(31.7)$ & 1 & 1 \\
\hline 10-20 times & $208(34.5)$ & $158(32.7)$ & $50(41.7)$ & 1.27 (0.79 to 2.05$)$ & 1.02 (0.59 to 1.77$)$ \\
\hline $30-40$ times & $100(16.6)$ & $80(16.6)$ & $20(16.7)$ & $1.00(0.55$ to 1.84$)$ & 0.74 (0.38 to 1.46$)$ \\
\hline$>40$ times & $104(17.2)$ & $92(19.0)$ & $12(10.0)$ & 0.53 (0.26 to 1.06$)$ & 0.58 (0.26 to 1.25$)$ \\
\hline \multicolumn{6}{|l|}{ Social support } \\
\hline Poor & $221(36.7)$ & $179(37.1)$ & $42(35)$ & $0.26(0.1 \text { to } 0.66)^{*}$ & 2.23 (0.79 to 6.26$)$ \\
\hline Moderate & $313(51.9)$ & $240(49.7)$ & $73(60.8)$ & 0.77 (0.5 to 1.18$)$ & 2.24 (0.81 to 6.17$)$ \\
\hline Strong & $69(11.4)$ & 64 (13.3) & $5(4.2)$ & 1 & 1 \\
\hline
\end{tabular}

${ }^{*} P<0.05,{ }^{* *} \mathrm{p}<0.01,{ }^{* * *} \mathrm{p}<0.001$.

†Others: divorced, widowed and separated.

AOR, adjusted OR; COR, Crud Odds Ratio; PTSD, post-traumatic stress disorder.

cases, these experiences induce various psychological and physiological stress reactions which may lead to PTSD, making PTSD one of the most common disorders among emergency responders. ${ }^{10}$

This study found the overall prevalence of PTSD among emergency responders to be $19.9 \%$, which is the same as the prevalence among emergency responders at the World Trade Center in the USA $(14.3 \%-17.4 \%) .{ }^{25} 33$ The correspondence in results between ours and previous studies could possibly be due to the similarity of the instrument used. Nonetheless, variations in the nature of work, duration of exposure and experience in the process might have played their roles in the marginal variations between the results. The $19.9 \%$ prevalence of PTSD was higher than those found in Norway (1.3\%), Japan $(1.6 \%-6.6 \%)$, China $(1.6 \%-3.1 \%)$, South Korea $(8.3 \%)$, South Africa (11.6\%) and Pakistan (15\%). ${ }^{12} 1921223435$ The possible difference could be due to the inclusion of other emergency responders, such as recovery workers, police officers and municipality workers, in addition to 
differences in study setting, instrument used and sociocultural differences.

PTSD among firefighters accounted for $19.9 \%$, of the $19.9 \%$ of the general PTSD prevalence among emergency responders, which is similar to the prevalence among firefighters in the USA, Australia, Germany and Kuwait. ${ }^{18} 25273436$ The similarity in the magnitude could be due to the study design and type of exposure. Conversely, this finding was lower than the study done in Australia, which was $31 \% .{ }^{37}$ The possible reason might be the nature or magnitude of the accidents they deal with.

The prevalence of PTSD among ambulance nurses accounted for $11.5 \%$ of all PTSDs, which is similar to (or higher than) findings from London $(6 \%)$ and Sweden $(5.2 \%) .{ }^{38} 39$ The similarity in the magnitude could be due to educational and professional preparations. Our finding was higher than the $22 \%$ seen in the UK. The difference could be due to sociocultural variations. Our finding was lower than the $5.6 \%$ reported in Brazil. ${ }^{17}$ The discordance could be due to the potential variations in the nature and magnitude of accident exposures that the firefighters deal with in their day-to-day practice.

Nations in different locale tend to evolve differently in response to the varying physical environment. Their cultures-as mechanisms of adaptation-prescribe the appropriate or desirable course of action when faced with environmental challenges such as emergency or risk situations. People's awareness of the environment, technological advancement, sense of duty or commitment to community welfare, definitions of risk and vulnerability, and so on vary between nations as they have different social values and cultural ethos, which they developed over centuries to meet the demands of the environment, and these variations account, at least partially, for variations among emergency responders in terms of their definition of risk, stressful situations and coping mechanisms, as well as their effects on mental health, in countries as varied as the USA, UK, Haiti and Ethiopia. This is only plausible, for as members of a community of people the culture of the group and its value system will impact members' assessment of situations as well as their risktaking or risk aversion behaviours.

The prevalence of PTSD among search and rescue workers accounted for $38.7 \%$, which is lower than $40 \%$ found in Haiti. ${ }^{40}$ The possible difference could be due to study design, sociocultural differences, and the nature and magnitude of the accidents covered in the study.

On the independent predictors of PTSD, family history of mental illness, length of service, duration of exposure and type of road traffic accident exposure were found to be statistically significant predictors of PTSD. Specifically, the greater likelihood of PTSD occurrence among those with family history of mental illness than those who had no such family history is similar with the results from Australia, where $55 \%$ of the survivors of a bush fire disaster with PTSD had family history of psychiatric conditions. In addition, psychological and genetic vulnerability made participants more highly predisposed to PTSD. ${ }^{41}$
On service years, the odds of developing PTSD increase with increase in work experience, which is similar to the case unravelled in America, ${ }^{14}$ which is possibly due to longer job experience that increased the number of potential traumatic events, which might aggravate PTSD symptoms (dose-response relationship). On the other hand, emergency responders exposed to traumatic events for longer hours are more likely to develop PTSD partly due to the sustained and longer emotional, psychological and physiological stress on victims. This result is different from the American case $($ mean $=10.0$ days $(\mathrm{SD}=3.8)),{ }^{14}$ which could be related to differences in sociocultural context and mechanisms of adaptation to their emergency responder roles.

On type of exposure, experiencing road traffic accidents doubles the odds of developing PTSD among emergency responders. This finding was supported by the results of studies conducted in Norway. ${ }^{22} 42$ Such findings could be partially explained by the relatively more shocking and devastating nature of road traffic accidents compared with the other forms of accidents. Moreover, the magnitude of accidents, distressed perception of the situation, or assisting or engaging in close contact with survivors might be unconsciously internalised to redefine self-image and/or bring catastrophic reaction to the event.

\section{Limitations of the study}

Recall bias might have occurred when the subjects were completing some of the items on the questionnaire, and we were unable to address individuals who had PTSD for further investigation and intervention because of the use of a self-administered questionnaire.

Additionally, by design, that is, a cross-sectional study design, this study is limited to unravel temporal relationships, and thus the observed/reported associations may not necessarily be causal. On the other hand, the results can be generalised only to a sample population. Nonetheless, although the study covers emergency responders of AFECA, its findings can be generalised to emergency responders in similar occupational and sociocultural contexts, that is, national technological advancement, culture of risk-taking and so on, and mostly in low-income/middle-income countries. As long as similarities between patterns of response to emergency and disaster situations in the study population and any population of concern could be established, the results of the study have a likelihood of generalisability. However, we have to take the transferability of knowledge outside the study's scope with caution as any study population is unique, with peculiar characteristics that make perfect transferability impossible. General insights and methodological notes could, however, be drawn in designing further studies or attempting at explanations in other settings.

One of the main problems with such types of cross-sectional studies is misclassification of exposure and outcome when participants are diagnosed with PTSD on a simple questionnaire. This is most likely due 
to the diagnosis which is based on a strict interview. This clerical and diagnosis error in the classification of exposure and outcome status can occur while the questionnaire states both exposure and the outcome at one point in time. In addition to this, the authors did not consider other mental health issues that can confound study outcomes. For instance, the presence and effects of anxiety and depression, which are commonly associated with PTSD symptoms and severity of PTSD, duration of mental illness, or exposure to other diseases were not covered in the study. Besides, the study did not cover predisposing factors such as personality traits or history of neurotic illness to PTSD, which could have increased misclassification of exposure as it risks overestimating PTSD. Furthermore, measurement errors could also occur, obscuring the evidence due to strong confounding errors. Therefore, we recommend further studies to focus on outcome measurement, including evaluations of measurement errors.

\section{CONCLUSIONS AND RECOMMENDATIONS}

Overall, the prevalence of PTSD was found to be high among emergency responders of the Authority. Family history of mental illness, length of service, duration of exposure and type of exposure such as road traffic accidents were found to be independent predictors of PTSD. Considering linkage with mental health service providers (Amanuel mental specialised hospital (AMSH) $)$ is recommended. One study shows that social support like family and friends can prevent work-related PTSD. ${ }^{43}$ Moreover, creating a sound and supportive organisational and working environment, and systematic training of employees, will also prevent the occurrence of the problem. ${ }^{44}$

Incorporating education/training on effective handling of stressful missions (stress management) and coping mechanisms in orientation/induction programmes and regular curriculum debriefing is strongly suggested. It is better to organise refresher courses, professional programmes and psychosocial support to those who have been on the job for longer periods. We recommend a PTSD-focused regular screening of emergency responders by trained health professionals to identify its nature and magnitude, as well as find plausible solutions. We believe the scale could adequately be deployed in further studies in the context of low-income/middle-income countries.

Acknowledgements The authors would like to thank the University of Gondar and the Amanuel Mental Specialized Hospital for their support and for allowing us to use the facilities. Our deepest gratitude goes to the entire staff of Addis Ababa Fire and Emergency Control and Prevention Service Authority for their collaboration.

Contributors YHB and SMA designed the study. YHB, SMA, TF, AT and MT performed the analysis and interpretation of the data, and drafted the paper. All authors prepared the draft manuscript, and read and approved the final manuscript.

Funding The authors have not declared a specific grant for this research from any funding agency in the public, commercial or not-for-profit sectors.

Competing interests None declared.

\section{Patient consent Obtained.}

Ethics approval The researchers obtained ethical clearance from the University of Gondar, College of Medicine and Health Sciences Ethical Review Board (UOG IRB). A formal letter was collected from the School of Medicine and submitted to AFECA, Head of Human Resources Department.

Provenance and peer review Not commissioned; externally peer reviewed.

Data sharing statement No additional data; all the data are included in the manuscript.

Open access This is an open access article distributed in accordance with the Creative Commons Attribution Non Commercial (CC BY-NC 4.0) license, which permits others to distribute, remix, adapt, build upon this work non-commercially, and license their derivative works on different terms, provided the original work is properly cited, appropriate credit is given, any changes made indicated, and the use is non-commercial. See: http://creativecommons.org/licenses/by-nc/4.0/.

\section{REFERENCES}

1. Heinrichs $M$, Wagner $D$, Schoch $W$, et al. Predicting posttraumatic stress symptoms from pretraumatic risk factors: a 2-year prospective follow-up study in firefighters. Am J Psychiatry 2005;162:2276-86.

2. Prince M, Patel V, Saxena S, et al. No health without mental health. Lancet 2007;370:859-77.

3. Kalia M. Assessing the economic impact of stress--the modern day hidden epidemic. Metabolism 2002;51(6 Suppl 1):49-53.

4. Heir T, Rosendal S, Bergh-Johannesson K, et al. Tsunami-affected Scandinavian tourists: disaster exposure and post-traumatic stress symptoms. Nord J Psychiatry 2011;65:9-15.

5. Breslau N, Chilcoat HD, Kessler RC, et al. Previous exposure to trauma and PTSD effects of subsequent trauma: results from the Detroit Area Survey of Trauma. Am J Psychiatry 1999;156:902-7.

6. Silva RR. Posttraumatic stress disorders in children and adolescents: handbook: WW Norton \& Company, 2004.

7. Kessler RC, Chiu WT, Demler O, et al. Prevalence, severity, and comorbidity of 12-month DSM-IV disorders in the National Comorbidity Survey Replication. Arch Gen Psychiatry 2005;62:617-27.

8. Luber M. Implementing EMDR early mental health interventions for man-made and natural disasters: Models scripted protocols and summary sheets: Springer Publishing Company, 2013.

9. Ma Z, Lu X, Chien SI, et al. Investigating factors influencing pedestrian injury severity at intersections. Traffic injury prevention 2017:1-6.

10. McFarlane AC, Atchison M, Rafalowicz E, et al. Physical symptoms in post-traumatic stress disorder. J Psychosom Res 1994;38:715-26.

11. Mitchell JT, Dyregrov A. Traumatic stress in disaster workers and emergency personnel. International handbook of traumatic stress syndromes: Springer, 1993:905-14.

12. Sakuma A, Takahashi Y, Ueda I, et al. Post-traumatic stress disorder and depression prevalence and associated risk factors among local disaster relief and reconstruction workers fourteen months after the Great East Japan Earthquake: a cross-sectional study. BMC Psychiatry 2015;15:1.

13. Skogstad L, Fjetland AM, Ekeberg Ø. Exposure and posttraumatic stress symptoms among first responders working in proximity to the terror sites in Norway on July 22, 2011 - a cross-sectional study. Scand J Trauma Resusc Emerg Med 2015;23:1.

14. Perrin MA, DiGrande L, Wheeler K, et al. Differences in PTSD prevalence and associated risk factors among world trade center disaster rescue and recovery workers. Am J Psychiatry 2007;164:1385-94

15. Corneil W, Beaton R, Murphy S, et al. Exposure to traumatic incidents and prevalence of posttraumatic stress symptomatology in urban firefighters in two countries. J Occup Health Psychol 1999;4:131-41.

16. Schlenger WE, Kulka RA, Fairbank JA, et al. The prevalence of posttraumatic stress disorder in the Vietnam generation: A multimethod, multisource assessment of psychiatric disorder. J Trauma Stress 1992;5:333-63

17. North CS, Tivis L, McMillen JC, et al. Psychiatric disorders in rescue workers after the Oklahoma City bombing. Am J Psychiatry 2002;159:857-9.

18. Everly G, Perrin P, Everly G. Psychological Issues in Escape, Rescue, and Survival in the Wake of Disaster. Mental Health 2008;12:21-30.

19. Ask E, Gudmundsdottir D. A longitudinal study of posttraumatic stress symptoms and their predictors in rescue workers after a firework factory disaster. Int J Emerg Ment Health 2014;16:316-21. 
20. Neria Y, Nandi A, Galea S. Post-traumatic stress disorder following disasters: a systematic review. Psychol Med 2008;38:467-80.

21. Razik S, Ehring T, Emmelkamp PM. Psychological consequences of terrorist attacks: prevalence and predictors of mental health problems in Pakistani emergency responders. Psychiatry Res 2013;207:80-5.

22. Skogstad L, Fjetland AM, Ekeberg Ø. Exposure and posttraumatic stress symptoms among first responders working in proximity to the terror sites in Norway on July 22, 2011 - a cross-sectional study. Scand J Trauma Resusc Emerg Med 2015;23:1-9.

23. McCrone P, Knapp M, Proudfoot J, et al. Cost-effectiveness of computerised cognitive-behavioural therapy for anxiety and depression in primary care: randomised controlled trial. $\mathrm{Br} \mathrm{J}$ Psychiatry 2004;185:55-62.

24. Crane MA, Levy-Carrick NC, Crowley L, et al. The response to September 11: a disaster case study. Ann Glob Health 2014;80:320-31.

25. Bennett P, Williams $Y$, Page N, et al. Associations between organizational and incident factors and emotional distress in emergency ambulance personnel. Br J Clin Psychol 2005;44:215-26.

26. Liu B, Tarigan LH, Bromet EJ, et al. World Trade Center disaster exposure-related probable posttraumatic stress disorder among responders and civilians: a meta-analysis. PLoS One 2014:9:e101491.

27. Wagner D, Heinrichs M, Ehlert U. Prevalence of symptoms of posttraumatic stress disorder in German professional firefighters. Am J Psychiatry 1998;155:66.

28. Balayan $\mathrm{K}$, et al. The impact of posttraumatic stress disorder on the quality of life: a systematic review. Int Neuropsychiatr Dis J 2014:2:214-33.

29. Hamblen J. What is PTSD? A handout from the National Center for PTSD: Washington, DC: National Center for PTSD, US Dept of Veterans Affairs. http://www. ptsd. va. gov/public/pages/handoutspdf/handout_What_is_PTSD. pdf (accessed Nov 2009).

30. Ruggiero KJ, Del Ben K, Scotti JR, et al. Psychometric properties of the PTSD Checklist-Civilian Version. J Trauma Stress 2003;16:495-502.

31. Abiola T, Udofia O, Zakari M. Psychometric properties of the 3 -item Oslo Social Support scale among clinical students of Bayero University Kano, Nigeria. Malaysian Journal of Psychiatry 2013;22:32-41.
32. Armstrong DM. Investigating well-being and mental health in Queensland fire-fighters: Queensland University, 2014.

33. Perrin MA, DiGrande L, Wheeler K, et al. Differences in PTSD prevalence and associated risk factors among World Trade Center disaster rescue and recovery workers. Am J Psychiatry 2007;164:1385-94

34. Ci S, Lan Y, Zhang Q, et al. [Analysis of posttraumatic stress disorder in rescuers and firefighters]. Zhonghua Lao Dong Wei Sheng Zhi Ye Bing Za Zhi 2015;33:448-50.

35. Ward CL, Lombard CJ, Gwebushe N. Critical incident exposure in South African emergency services personnel: prevalence and associated mental health issues. Emerg Med J 2006;23:226-31.

36. Townsend M, Weisler MRH. Post-disaster psychiatry: lessons from Katrina: med-scape psychiatry and mental health, 2007.

37. Werner HR, Bates GW, Bell RC, et al. Critical incident stress in victoria state emergency service volunteers: characteristics of critical incidents, common stress responses, and coping methods. Aust Psychol 1992;27:159-65.

38. Misra M, Greenberg N, Hutchinson C, et al. Psychological impact upon London Ambulance Service of the 2005 bombings. Occup Med 2009:59:428-33.

39. Chung I-S, Lee M-Y, Jung S-W, et al. Minnesota multiphasic personality inventory as related factor for post traumatic stress disorder symptoms according to job stress level in experienced firefighters: 5-year study. Ann Occup Environ Med 2015;27:1.

40. van der Velden PG, van Loon P, Benight CC, et al. Mental health problems among search and rescue workers deployed in the Haïti earthquake 2010: a pre-post comparison. Psychiatry Res 2012:198:100-5.

41. Keane TM, Fisher LM, Krinsley KE, et al. Posttraumatic stress disorder, Handbook of prescriptive treatments for adults: Springer, 1994:237-60.

42. Carson MA, Paulus LA, Lasko NB, et al. Psychophysiologic assessment of posttraumatic stress disorder in Vietnam nurse veterans who witnessed injury or death. J Consult Clin Psychol 2000;68:890-7.

43. Regehr C, Hill J, Glancy GD. Individual predictors of traumatic reactions in firefighters. J Nerv Ment Dis 2000;188:333-9.

44. Skogstad M, Skorstad M, Lie A, et al. Work-related post-traumatic stress disorder. Occup Med 2013;63:175-82. 